\title{
DE AANKLEEDING VAN EEN AMBTSWONING ONDER DE COMPAGNIE.
}

\author{
DOOR
}

Dr. F. W. STAPEL.

Ondanks de sedert eenige decenniën duidelijk-waarneembaar groeiende belangstelling voor onze Indische Geschiedenis blijft het een feit, dat wij nog maar zeer weinig weten van het gewone alledaagsche leven onzer 17 de en 18 de eeuwsche voorouders in den Oost, met name op de buytencomptoiren. Voor wat Batavia betreft heeft De Haan's voortreffelijke jubileumwerk ${ }^{1}$ ) ons niet slechts belangwekkende en vermakelijke kijkjes op dat leven geschonken, maar daardoor tevens den lust naar meer gewekt. Valentijn en een aantal mindere goden vertellen ons soms aardige dingen uit het leven op Ambon en andere veelbezochte centra, maar aangaande het bestaan op tal van ver-af gelegen oorden, waar 's Compagnies vertegenwoordigers vaak maanden lang geen Nederlandsch schip zagen en dus geen landgenoot spraken buiten het kleine kringetje medeambtenaren, hebben wij slechts een uiterst vage voorstelling. Oordeelen wij juist, als wij ons dat leven over het geheel als doodelijk vervelend voorstellen, van een grijze eentonigheid, die vele misbruiken verklaart? Hoe waren de kantoren, pakhuizen en woningen der suppoosten ingericht op Agra en Basra, in Siam en Tonkin, op Ligor, Djambi en Formosa? Hoe ging men gekleed en hoe was de dagindeeling? Wat deed men na werktijd en wàs er wel een vaste werktijd? Wat schafte de pot? Kocht men zijn meubelen ter plaatse of bracht men die van elders mee? Hoeveel bedienden of slaven hield men?

Ook vragen van hooger plan rijzen. Wie gaf de kinderen der gehuwde ambtenaren onderwijs en welke hulpmiddelen had men daarbij ? Bestond er belangstelling voor wetenschap en kunst en bezat men

1) Dr. F. de Haan, Oud-Batavia. Weltevreden 1922.

2) François Valentijn, Oud- en Nieuw Oost-Indiën. Dordrecht-Amsterdam, 1724-1726. 
de daarvoor benoodigde boeken en ander materiaal ? Hoe was de omgang met de inheemsche bevolking en gaf men zich ook moeite om de landstaal te leeren? Vernam men ook het belangrijkste nieuws uit patria en de andere Europeesche landen?

Slechts een uitgebreide en veelzijdige particuliere briefwisseling zou ons op al deze vragen de gewenschte antwoorden kunnen verschaffen, maar zoodanige correspondentie bezitten wij voor de $17 \mathrm{de}$ en 18de eeuwsche buitenkantoren helaas niet. Over het algemeen waren onze voorouders, die ambtelijk veel rapporten moesten samenstellen en boeken bijhouden, slechte briefschrijvers, terwijl bovendien de Compagnie door haar censuur (alle brieven moesten open in de ,.gemene dooze" worden meegegeven) den lust tot intieme correspondentie niet aanmoedigde. Vele brieven gingen, ook als zij hun adres bereikten, later verloren en ten slotte verzet het Hollandsche karakter zich tegen het publiek maken van wat voor besloten kring is bestemd. Zoo missen wij, zonder veel uitzicht op herontdekking, een der voornaamste bronnen van de "histoire intime” der Nederlanders onder de Compagnie.

$\mathrm{Er}$ is nog een andere, schoon minder belangrijke, bron voor dit deel der geschiedenis, die echter zoo goed als uitsluitend voor $\mathrm{Ba}$ tavia geldt. Wij bedoelen de registers van Wees- en Boedelmeesteren en de, eerst geschreven, later gedrukte, lijsten van het Vendukantoor. $Z_{i j}$ laten ons zien wat bij de liquidatie van een huishouden, door overlijden of vertrek, voor dên dag kwam en wat dit bij publieken verkoop opbracht. Met de tienduizenden bewaard gebleven testamenten geven ons de overzichten dier boedels althans een denkbeeld van de inrichting der huizen, van aantal en waarde der slaven en meubelen, muziekinstrumenten, boeken, schilderijen, porcelein. Deze boedelbeschrijvingen ontbreken echter zoo goed als geheel voor de buitenkantoren. Overleed daar een ambtenaar, dan haastten zijn collega's zich de nagelaten bezittingen te verkoopen, waarna zij de opbrengst in 's Compagnies kassa stortten en op de rekening van den overledene als tegoed boekten. Slechts uiterst zelden vindt men een opgave van de verkochte objecten.

De schaarschheid dezer gegevens doet het ons te meer waardeeren als wij er een enkele maal een ontmoeten. Zoo vonden wij in de uit Indië „Overgecomen brieven 1645, 2de deel, vervolgh” het verslag der overdracht van het gouverneurschap van Formosa door Maximiliaan Lemaire aan zijn opvolger Françös Caron, op 30 September 1644. Een daarbij behoorende specificatie draagt den volgenden titel: 
Lijste ofte Memorie der contanten, gout, coopmanschappen, provisiën, amunitie van oorloge, scheepsgereetschappen etc., welcke op dato ultimo September (1644) by gecommitteerde raetspersonen op 't sluyten der negotieboecken door den E. president Maximiliaen Le Maire aen den E. Heer François Caron, Raet van India, gouverneur ende directeur deser plaetse, sijn getransporteert ende overhandicht, sijnde deselve berustende ende bevonden als volcht, namentlijck:

Daarop volgt dan een omstandige opgave van alle aanwezige gelden, koopmanschappen, kanonnen, schepen, materialen, gereedschappen, enz. Wij zullen van dit alles niets overnemen, met uitzondering, curiositeits-halve, van een der afdeelingen, waarin een aantal restanten zijn ondergebracht, waarmede men elders geen raad wist, en wel onder het hoofd Des Compagnies lijffeygenen ende noch eenige ongetaxeerde goederen. Dit lijstje bevat:

133 Compagnies lijffeygenen

3 stucx slijpsteenen

42 stucx brandemmers

199 stucx hoornbeesten

1 ezel

5 clocken

2 stucx bellen.

Verder willen wij ons beperken tot het „huysraet”. Uit de omschrijving blijkt, dat hier sprake is van wat wij dienstmeubelen zouden noemen, namelijk huisraad, dat eigendom van de Compagnie was en bleef. Voor een deel bevindt het zich in de kasteelen op Tajoewan, het bekende Zeelandia, en het wat Zuidelijker gelegen Saccam, voor een ander deel in het gouverneurshuis in de stad.

Huysraet, soo hier in Tayouan als op Sacam:

3 zilvere candelaers ende 1 schotelken

1 copere caerscroon

2 copere schalen met hun gewicht

1 fijne daetchie ${ }^{1}$ )

32 stucx stoelen

2 Japanse taylgewichten ${ }^{2}$ )

1) Daats, Chineesche unster of weegstok.

2) Tayl of thael, Chineesch en Japansch gewicht van $371 / 2$ gram. Het was onderverdeeld in 10 maas $=100$ condrijn $=1000$ rin en diende voor het afwegen van edele metalen. 
3 slaepcoyen

1 uyttreckende taeffel

8 stucx taeffellakens

125 stucx servetten.

Met uitzondering van de gewichten, die steeds onder contrôle moesten worden bewaard, is dit alles klaarblijkelijk bestemd voor officieele feestelijkheden, waarbij de gasten zoo noodig dan ook gebruik konden maken van de slaepcoyen!

Vervolgens vindt men een opgave van de dienstaankleeding der woning van den gouverneur. Wij hebben er elders al eens op gewezen, hoe eigenaardig daarbij de opgave is van de vele schilderijen; zij demonstreert, dat ook in Indië de Hollandsche belangstelling voor schilderijen levend bleef.

In 't Gouverneurshuys:

22 stucx Hollantse schilderyen, te weten:

14 stucx van 't huys Nassauw, etc.

1 , van Marias bootschap

1 , Abrahams knecht in Mesopotamië, etc.

1 ,, Christus wandelende naer Emaus

1 , de Worstelinge Jacobs tegen den engel

1 , de Camerlingh van de coninginne van Candatiën

1 , van de Samaritaen

1 ,, de Reyse van den jongen Tobias

1 „ een onweder ter zee

\section{2 stucx}

1 groote taeffel

1 groote verlacte

1 dito vergulde ledecanten

3 stucx copere candelaers

8 stucx roode lakense cussens

1 dito root taeffelcleet.

Ten slotte zij vermeld, dat zich onder de gebouwen nog een huis van de Compagnie bevindt, omschreven als ,een tuyn ofte erff met sijn huysinge, gelegen in de stad Zeelandia, aan de N.syde van de Kercqstraet”. Dit zal òf bestemd zijn geweest om vreemde bezoekers of gezanten te logeeren, ò het was de dienstwoning van den ,secunde", den vervanger van den gouverneur. 
Op den dag af heeft Caron het gouverneurschap van Formosa twee jaar vervuld; 30 September 1646 droeg hij het over aan Pieter Anthonisz. Overtwater, en ook van deze overdracht bezitten wij een gespecificeerde opgave (Overgecomen brieven 1647, tweede boeck, 1e deel). Een vergelijking toont aan, dat de nederzetting op Formosa zich nog in de stijgende lijn bevindt. Uit de „,rommelrubriek” blijkt, dat het aantal lijfeigenen is geklommen tot 174 . Ook de hoornbeesten zijn toegenomen, terwijl er bovendien 84 paarden worden genoemd, namelijk „12 stucx Balyse paerden” benevens ,72 stucx paerden in 't velt loopende". Het aantal gebouwen is belangrijk vermeerderd; behalve de bovengenoemde treffen wij aan ,9 stene huysen" van verschillende grootte en op verschillende plaatsen gelegen, klaarblijkelijk ambtenaarswoningen. Nieuw zijn verder „1 sieckenhuys, 1 koestal en 1 paerdestal". Het aantal stoelen in het kasteel is nu op 34 gebracht, terwijl er thans bij staat, dat ze van "quiatenhout” zijn, dat is djati-hout (ki-jati). Op den vloer ligt nu een ,alcatijff", een Arabisch karpet, terwijl aan den wand een ,grote cederhoute spiegel” prijkt.

Ook het gouverneurshuis is er op vooruit gegaan. De 22 genoemde schilderijen hangen er nog steeds, maar hebben nu gezelschap gekregen van een viertal nieuwe, namelijk:

1 de historie van Rebecca

1 van 't huys Nassouw

1 schilderij van den ouden prins (Vermoedelijk Willem I)

1 de slach van Marten Herbertsen Tromp in Duyns.

Dit laatste is actueel, daar die slag in 1639 plaats had. Verder worden genoemd twee wandkaarten, en wel een van geheel Formosa en een van Tajoewan.

Ook het andere meubilair is vermeerderd; er zijn thans 36 kussens, twee tafellakens, 6 tafels en twee voetbanken. Klaarblijkelijk wordt er nu dus ook op damesbezoek gerekend.

Eindelijk het ,thuynhuys”, waarvan in 1644 geen aankleeding genoemd werd. Dit bevat thans:

1 grootte taeffel met een root laeckens cleet

1 dito wat cleender, met een blauw cleet met franje

1 dito noch cleender, sonder franje

9 blauwe cussens en 11 stucx stoelen

2 houte bancken

7 stucx Chinese schilderijen 
2 groote copere candelaers

1 vergult geweerrack

60 stucx alderhande porceleynen

8 verlacte backen

1 copere watergieter

2 isere schoppen. 